Grumach in Berlin will be convinced by these twenty pages, and for the rest of us the test of the decipherment is in the further work based upon it, not in the endless repetition of the sterile quarrel which has been carried on for nearly five years in both learned journals and the Sunday newspapers. Much more would have been gained by devoting these twenty pages to further exploration of the actual work of decipherment.

The final chapter, "Life in Mycenæan Society", though it has little of the air of polemic about it, is a deceptively valuable contribution to a still vigorous debate. Indiscipline and romantic guesswork did not come to a sudden end with Ventris's decipherment : they merely moved from decipherment to interpretation. Enthusiasm far outran the evidence, which is severely limited by both the incompleteness of the decipherment (only six years old, after all) and the very restricted contents of the tablets. Inevitably, the layman's knowledge comes from the popular presentations, and they have tended to exaggerate what we know, sometimes quite wildly. It is therefore useful to have the weight of Chadwick's authority, in a popular work, placed in the scales on the side of caution and of frank recognition of how little we still know about Mycenæan society.

M. I. FINLEY

\section{WESSEX LONG AGO}

Wessex Before the Celts

By Dr. J. F. S. Stone. (Ancient Peoples and Places, Vol. 9.) Pp. 207 (72 plates). (London: Thames and Hudson, Ltd., 1958.) 25s. net.

TOBODY who knew the late Dr. J. F. S. Stone 1 can read this book, "Wessex", without much sorrow at his sudden and untimely death. Indeed, the work has only been finally completed and passed for press thanks to the kindness of Prof. Stuart Piggott.

The book covers a considerable area of ground and deals with a long period of time-the Mesolithic epoch until the arrival of the Celtic folk. There are 148 pages of text, a reasonable bibliography and 38 pages of illustrations. Nowadays in Great Britain there are a large number of amateurs interested in archaeology, and this book, like the others in the series, is designed for them. The space available is barely sufficient to give a general picture of the Wessex scene during the various periods and specialists must not expect any detailed accounts. The Palæolithic period is omitted, and the work starts with a few words on the Mesolithic (forest) cultures as a background to a rather fuller account of the first Neolithic inhabitants. There follow a few pages devoted to the various barrows of these times, and the flint mines whence came the raw material for tool making. The later Neolithic invasions and the coming of the Beaker folk are next considered in greater detail, and these lead on naturally to an excellent account of Stonehenge, Avebury, etc. A couple of chapters on Bronze Age times carry the story on to the epilogue, "Celtic Wessex". The book as a whole is a good example of its kind and can be recommended without reserve for those readers, nonspecialist but interested generally in the past, for whom it was composed. M. C. BURKITT

\section{THE INDIAN AGRICULTURAL SERVICE}

\section{Agricultural Research in India}

Institutes and Organisations. By Dr. M. S. Randhawa. Pp. $v+448+79$ plates. (New Delhi : Indian Council of Agricultural Research, 1958.) Rs. 20 ; 40s. ; 6 dollars.

7 HREE facts will suffice to make the importance of agricultural research to India abundantly clear: (1) that three-quarters of the population depend directly on agriculture for a living; (2) that the need for national action to improve agriculture was first officially stated by committees set up in 1880,1888 and 1901 with the ominous name of Famine Commissions ; and (3) that each year now food has to be grown for 5,000,000 additional people, so that only to maintain present standards of nutrition demands a steady and continuous rise in production.

This handsome volume, prepared by the VicePresident of the Indian Council of Agricultural Research, shows how much the Indian Government is spending and how it organizes research in its attempts to get the knowledge that will be needed before the fear of famine can be banished and the living standards of the bulk of the population increased. The book is less one for reading than for reference, with its main value to find out where different crops and problems are being studied, who is working on them, and what body is responsible for finance, administration and for co-ordinating work done in the different States. Nevertheless, the descriptions of the work at the various institutes are detailed enough to show that, despite the very many problems still waiting a solution, much has been found out that could improve yields by the better feeding of crops and livestock, by the control of pests and diseases, by irrigation and by the growing of higher-yielding varieties. The book deals only with research, and some information about the important and difficult problem of getting discoveries applied would have added to its value.

It is necessary only to turn the pages to be impressed by the growth in agricultural research, from its beginnings in 1905 at the Imperial Agricultural Research Institute, Pusa, Bihar, which was destroyed by the earthquake of 1935 , to the present nine central research institutes, several commodity research in. stitutes and the more than thirty research stations and farms in the different States. The photographs leave no doubt that many large and magnificent laboratories have been built, but provide little evidence on the standard of the physical equipment. However, staff is the most important equipment of any research establishment, and here also the numbers are impressive, at least at first sight. The Indian Agricultural Research Institute, the new Pusa based on Delhi, with about 350 graduates, is probably much the largest in the whole Commonwealth, and some of the others are also of considerable size. Even so, India is so vast and conditions so varied that many more could undoubtedly be justified, for as a proportion of the population engaged in agriculture the number is much below that in many other countries. But quantity of staff is less important than quality; although government may provide new buildings, physical equipment, organizing committees and lakhs of rupees for salaries, only the research workers can produce results. It is no exaggeration to say that the prosperity of India 